\title{
Understanding Swiss Drug Policy Change and the Introduction of Heroin Maintenance Treatment
}

\author{
Riaz Khan ${ }^{\mathrm{a}}$ Yasser Khazaal $^{\mathrm{a}}$ Gabriel Thorens $^{\mathrm{a}} \quad$ Daniele Zullino ${ }^{\mathrm{a}}$ \\ Ambros Uchtenhagen ${ }^{b}$ \\ a Division of Addictology, Department of Mental Health and Psychiatry, University Hospitals Geneva, Geneva, and

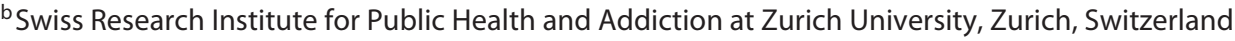

\section{Key Words \\ Drug policy $\cdot$ Knowledge brokering $\cdot$ Heroin $\cdot$ Harm \\ reduction · Addictions $\cdot$ Opiate prescription}

\begin{abstract}
Aims: The aim of this paper is to illustrate how Switzerland was able to play such a pioneering role in the field of addiction treatment, in creating a drug policy that includes the medical prescription of diacetylmorphine (heroin). The paper will also describe the role of knowledge brokering processes and coalition building in the different phases of the development of the Swiss drug policy. Discussion: The medical prescription of diacetylmorphine was the exotic element of the Swiss drug policy of 1991 and probably still is one of the most controversial practices in clinical medicine despite its documented effectiveness. Coalitions of change actors, across stakeholder groups from many professions and politicians on various levels, succeeded in formulating and starting initiatives for a new drug policy and its innovations. Clear, shared objectives and a common feeling of urgency brought the coalitions together. Conclusion: In the case of Switzerland, the Confederation took a leading role by facilitating communication, encouraging scientific knowledge and bringing the various stakeholders on a platform to de-
\end{abstract}

liver a consensual political policymaking basis. This was facilitated by the Swiss direct democracy system. Sustained dialogue between researchers and the users of research enhances the likelihood of research affecting policy.

(c) 2014 S. Karger AG, Basel

\section{Introduction}

The medical prescription of diacetylmorphine (heroin) was the exotic element of the new Swiss drug policy of 1991 and still is probably one of the most controversial practices in clinical medicine despite its documented effectiveness. Following the Swiss prospective naturalistic cohort study which demonstrated feasibility, safety and cost-effectiveness [1-4], a number of randomised controlled trials in other countries confirmed the role of prescribed diacetylmorphine as an effective therapeutic agent $[2,5-7]$. Although these trials differed in design and outcome criteria, they all had in common the entry criteria (heroin addicts for whom other treatment including methadone maintenance had failed) and the program characteristics (supervised injections in the framework of a comprehensive assessment and treatment programme). A Cochrane review of 8 randomised controlled trials con-

\section{KARGER}

E-Mail karger@karger.com

www.karger.com/ear
(C) 2014 S. Karger AG, Basel

1022-6877/14/0204-0200\$39.50/0
Yasser Khazaal

Geneva University Hospitals Grand Pré, 70C

$\mathrm{CH}-1206$ Geneva (Switzerland)

E-Mail yasser.khazaal@ @cuge.ch 
cluded: 'The available evidence suggests an added value of heroin prescribed alongside flexible doses of methadone for long-term, treatment-refractory, opioid users, to reach a decrease in the use of illicit substances, involvement in criminal activity and incarceration, a possible reduction in mortality; and an increase in retention in treatment' [8]. Research evidence, clinical experience and policy aspects have been presented in an insight publication by the European Monitoring Centre for Drugs and Drug Addiction EMCDDA [9].

An essential difference in design and terminology occurred during the entire process. The Swiss project at first was conceived as a scientific experiment; feasibility, safety and efficacy were to be tested. The original design was a randomised controlled clinical trial with three arms (injectable heroin vs. injectable morphine and injectable methadone [10]). Therefore, the experiment was named PROVE ('Projekt zur ärztlichen Verschreibung von Betäubungsmitteln', project on medical prescription of narcotics). However, problems with intravenous morphine and methadone became obvious very soon and had to be stopped; the trial was transformed into a naturalistic prospective cohort study without controls (except one sub-study with a waiting list design [11]). The essential feature and innovative element was the use of diamorphine as a medicine for substituting street heroin. In order to prevent a common misunderstanding, after the experimental phase, the therapeutic program was renamed heroin-assisted treatment HAT ('heroingestützte Behandlung $\mathrm{HeGeBe}$ ). In comparison to the long-standing British practice to hand out heroin prescriptions to addicts, the Swiss concept used supervised heroin injections as a pharmaceutical tool in the framework of a comprehensive assessment and treatment program. This was necessary for the target group of previously treatmentresistant addicts, and the re-naming was necessary for the implementation and consolidation phase in order to avoid the notion of 'just handing out heroin'. The new term was increasingly used internationally. However, in analogy to other agonist maintenance treatments of opioid dependence, the appropriate term used here is heroin maintenance treatment.

Based on the evidence and clinical experience, heroin maintenance treatment is by now part of the treatment system in 6 countries. However, all this has not led to an unanimous acceptance amongst the medical community. A wide range of concerns and expected risks for patients, for other treatment approaches, for society at large were raised from the beginning [10] and had to be carefully examined in the light of outcomes [12]. Also, ethical ar-

Understanding Swiss Drug Policy Change guments are mentioned by opponents and discussed [13, 14].

The aim of this paper is to illustrate how a basically conservative country like Switzerland was able to play such a pioneering role in the field of addiction treatment and in creating a drug policy which includes the medical prescription of heroin, as part of the therapeutic arsenal.

The paper at hand is not a systematic review based on literature search, but a case study including an application of selected relevant theoretical models.

\section{The Paradigm Change in Swiss Drug Policy of 1991}

Unlike other countries of the Organisation for Economic Co-operation and Development (OECD), Switzerland does not have a government and an opposition. In the executive body, the Federal Council (Bundesrat), the four largest parties from the political landscape are represented. In 1991, the Federal Council decreed a new national drug policy, backed up by a shared policy platform of three major political parties [15].

Before 1991, drug policy was largely determined by the Swiss narcotic law, revised in 1975. It was based on strict prohibition, even of consumption and preparatory acts for personal use. The treatment system diversified during the following years, including numerous drug-free therapeutic communities and agonist maintenance therapies (methadone, later also buprenorphine), but medical and social support for illegal injectors was considered to facilitate the habit. Provision of injection equipment was prohibited. This policy could not prevent a steady increase in the incidence and prevalence of drug use, especially of heroin injecting and its sequelae (increase in mortality, in blood-borne infections, in drug-related criminality and in drug trafficking). Finally, the misery and violence in the open drug scenes in major cities became intolerable, incompatible with the self-image of a well-organised society, and a challenge for a radical policy change. These massive open drug scenes in 'needle parks' were a result of repeated failure in dissolving drug scenes in more vulnerable residential or business areas; instead of chasing them around, police profited from observing and controlling criminal activities in a central location.

The new policy introduced harm reduction as a 4 th pillar besides prevention, treatment and law enforcement. It also called for innovative approaches in all pillars, including medical prescription of heroin, and for appropriate documentation and evaluation of such innova- 
tions. It did not impose a special action plan, but exposed options for innovation, collaboration and evaluation, and invited creative answers to the existing or emerging problems. The following objectives prevailed: to stabilise and, in the long term, to reduce the number of persons dependent on hard drugs, and to reduce problems relating to the consumption of illicit drugs and the effects of such problems on society. In accordance, a number of measures were implemented by the Federal Office of Public Health in order to manage the rising drug problem [16].

On the basis of this new policy, a prospective cohort study with medical prescription of heroin could be prepared, implemented and evaluated. It included a number of clinical and pharmacological sub-studies. When the positive outcomes of the study were presented [4], endorsed by an international expert committee of World Health Organisation [17], the Federal Government passed an executive order in 1998 as a legal basis to continue heroin-assisted treatment for the defined target group. Follow-up studies confirmed its feasibility and safety [1], so that it could be adopted as an additional regular therapeutic programme for otherwise treatment-resistant heroin addicts, financed by health insurance, and prolonged by national parliament in 2003 .

However, opposition to the new policy and especially to heroin prescription was raised and led to two initiatives for a national referendum. In the Swiss political system, referenda must be held if 50,000 citizens request a vote on a federal law, or if an initiative to amend the constitution is supported by 100,000 signatures collected within 18 months. In 1993 and 1994, two popular initiatives (referendum requests) were presented, with opposite objectives. The initiative entitled 'Youth without Drugs' called for a strict, abstinence-oriented drug policy that emphasised the role of repression, along with prevention, and drug-free therapy. It also was seeking to prohibit medical prescription of narcotics. The other initiative entitled 'For a Reasonable Drug Policy' ('Droleg') proposed the opposite, namely, the decriminalisation of drug use, and cultivation of plants used to produce drugs, as well as legal possession and purchase of drugs for personal use. Furthermore, it implied that the state supervise cultivation, import, and production of narcotics and, thereby, make trade in narcotics for non-medical purposes possible within a defined legal framework providing protection of youths and a ban on advertising.

Both initiatives were rejected by referenda in 1997 and 1998 , respectively, with 70 and $74 \%$ of votes. This was understood as a confirmation of the new national drug policy.
When facing the popular initiatives and in order to create a legal basis for the new drug policy, an expert Commission (the 'Schild Commission') was set up in February 1996 by the Swiss Federal Department of Home Affairs, in view of a revision of narcotic law [18]. The commission's report put forward several recommendations, including a continuation of the medical prescription of heroin as an additional therapeutic approach, provided that the good interim results could be confirmed. After a formal consultation of the Schild Commission report by the authorities, the majority of cantons, parties, and expert organisations expressed acceptance of the medical prescription of heroin as an option for therapy and harm reduction practice.

\section{How Can Such a Paradigm Change Be Achieved?}

The Swiss referendum democracy requires a considerable degree of citizen engagement and participation. Introducing novel approaches for handling sensitive problems, such as those posed by psychoactive drugs, means that the public at large, the voters, need to be well informed and prepared about the issues involved. This, in turn, requires a well-organised documented information strategy based on synergies between scientific evidence and political skills. In order to introduce a new policy, therefore, a lengthy consensus-forming process is needed and, at the end of the process, citizens are entitled to accept or turn down parliamentary decisions. This specificity of Swiss politics enhances networking, coalition building and knowledge brokering activities at various levels (community, decision-makers and numerous stakeholders) in the policy process.

Social science has developed various theoretical concepts for a better understanding of such processes. They provide a framework for understanding how societal and political resistance against major innovations with unknown consequences may be overcome. Two types of theories will be considered here: on knowledge brokering, and on coalition building.

\section{Knowledge Brokering}

The theory and practice of knowledge management, knowledge transfer and knowledge brokerage is an emerging field and has been deployed for some time by organisations such as the Canadian Health Services Research Foundation [19-21]. Knowledge brokering is one of the human forces behind knowledge transfer. It is a dynamic activity that goes well beyond the standard no- 
tion of transfer as a collection of activities that helps move information from a source to a recipient.

Brokering focuses on identifying and bringing together people interested in an issue in order to develop evidence-based solutions. It helps build relationships and networks for sharing existing research and ideas and stimulating new solutions. Knowledge brokering is then a process supporting evidence-based decision-making by encouraging the connections that ease knowledge transfer. The process may benefit from a supportive organisation able to allow a collaborative environment and sufficient resources for the job, processes.

The characteristics of knowledge brokering are [21]:

- Organizing and managing joint forums for policymakers and researchers.

- Building relationships of trust.

- Setting agendas and common goals.

- Signalling mutual opportunities.

- Clarifying information needs.

- Commissioning syntheses of research of high policy relevance.

- Packaging research syntheses and facilitating access to evidence.

- Strengthening capacity for knowledge translation.

- Communicating and sharing advice.

- Monitoring impact on the know-do gap.

Translating research findings into health policy focuses on organizing the interactive process between the producers and users of knowledge so that they can co-produce feasible and policy options based on research issued information. The strategy aims to bridge the gaps between research findings and evidence required in policymaking.

Health research and policy-making work in different settings, each with their own professional culture, resources and time frames. The communication gap between these stakeholders is subordinated to the different agenda priorities. In the case of the policymaker, there is rarely a clear message about the policy challenges; the rapid turnover in the political setup focuses on the specific context to allow for timely and appropriate research agendas.

The research scientist, on the other hand, often produces scientific evidence not particularly tailor-made to be used by the policymaker for the various contexts during his period in government.

Three elements have a major role in enhancing research-policy translation [22-25]:

- Willingness, on the part of the researcher, to justify the policy implications of his or her findings.

Understanding Swiss Drug Policy Change
- Inclusion of policymakers in negotiating the frame of reference before research is undertaken.

- Trust with an ongoing commitment between researchers and policymakers.

\section{Coalition Building}

Democratically organised societies have to find ways how to proceed when in need of a reformulation of strategies in face of new societal and technological developments, especially in dealing with controversial preferences and interests. The area of drug policy adjustment presents an excellent example for discussing the problem and the process of coalition building for finding acceptable answers to new challenges.

Useful network theories and models have focused increasingly on how political, cultural and technological innovation and change happens [26]. A common denominator of such approaches is a system-based view of societies, with subsystems and networks of actors initiating and supporting innovation, rather than single innovators and actors. Well-known examples are the advocacy coalition framework (ACF) [27], social network theory [28], normalisation process theory [29], and diffusion of innovations theory [30,31]. A more general perspective offers the theory of societal learning [32].

A further development is the actor-network theory (ANT) which includes non-human factors into the network analysis [33, 34]. The ANT has been applied, among others, to the health field. It is especially interesting for analysing drug policy change as it can include epidemiological change as a factor. It has also met substantial criticism; it is argued that research based on ANT perspectives remains descriptive and cannot explain social processes. The ANT is more interested in exploring how actor-networks get formed, hold themselves together, or fall apart.

Another step was the development of tools for mapping out and interpreting scientific controversies in complex matters in order to facilitate orientation and coalition forming [35].

\section{A Process Analysis of Implementing and Consolidating the New Drug Policy and Heroin Maintenance Treatment}

Both types of theories can be applied to analysing the paradigm change described above. The coalition building theory is more appropriate for our understanding of the preparatory and implementation phases of the process, 
while knowledge brokerage theory helps to understand the consolidation phase.

\section{Coalition Building in the Early Phases}

The process of re-shaping drug policy was analysed on the basis of the ANT and the ACF, in a number of case studies in Swiss cities.

A systematic ANT-based analysis in 4 cities (Bern, Chur, St. Gallen, Zurich) built first on the empirical identification of institutions, actors, competences and procedures which are relevant in the drug policy area was followed by an analysis of the specific interaction and dependence patterns. Two separate networks are in focus: the policy network and the decision-making network. Moving beyond the ANT, specific hypotheses on determinants were tested. As a result, the independent variables shaping the policy network are the size of the city, the size of the local drug problems (including the HIV epidemic and the correspondent media interest), the dominant political parties and the administrative structure. On the other side, the decision-making network is mainly determined by the structure and characteristics of the policy network, and less on the politically and administratively preferred types of regulatory measures. The role of coalition building is well demonstrated [36].

Another analysis was using the ACF, complemented by social movement theory and the two concepts of mobilizing structures and political opportunity structures [37-39]. The ACF understands the policy process as a competition between coalitions of actors who advocate beliefs about policy problems and solutions. In the case of Swiss drug policy, this means a competition between a prohibitionist and a harm-reduction coalition. The latter developed the belief that measures to prevent bloodborne infections must override the inefficient belief in preventing drug use in an abstinence-only perspective not only for the sake of users, but in order to protect the general population as well. The implementation of the harm reduction policy had to be tailored, in a second step, to the needs of public order, reducing public nuisance. The concept of 'Stadtverträglichkeit' (urban compatibility) of harm reduction measures was introduced as an important additional element.

Who were the change actors and what were their initiatives in the coalition building processes in the city of $\mathrm{Zu}$ rich? The most diverse organisations and persons started to react, at first without a shared action plan, mostly along a strategy to avoid specific negative aspects, which in the course of action was labelled 'harm reduction'. The Medical Association recommended the provision of sterile sy- ringes and needles, a coalition of infection specialists and the Red Cross organised blood testing and hepatitis B immunisation right in needle park, ad hoc groups of concerned citizens and parents offered meals, a medical emergency team intervened in innumerable overdose cases, and medical, social and psychiatric support was provided in easily accessible drop-in centres. A specialised NGO for risk-free use of drugs was set up and opened a low-threshold methadone clinic, without obligatory counselling and urine controls, but with visual intake control to avoid diversion and overdose. In 1988, a 'Drogen Charta' was set up and published by a heterogeneous coalition of politicians, professionals, academics and NGOs. These initiatives have been well documented and described $[10,39,40]$.

What was the official reaction? After initial rejection, low-threshold methadone prescribing was tolerated, as well as injection rooms and continued use in shelters. The Social Department in the City Administration changed from a repressive attitude against rebellious and drug using youth to an active policy of supporting measures to prevent health and social deterioration of users. The City Government became an active promoter of prescribing heroin to chronic heroin users; this initiative was taken up by the Federal Expert Committee on Drugs and finally by Federal Government, in the framework of the national 4-pillar drug policy of 1991 . Harm reduction approaches were considered to be admissible within the framework of national legislation and international conventions by specially mandated law experts.

The change process described above evolved within less than a decade. It was not prepared, not driven by a ready-made concept of a new policy or action plan. Nor was it based on a consistent concept of an open society fostering experimentation and innovation. It was rather driven by the unacceptable realities clashing with the cherished self-image of professionals in the health and social sector of being competent and efficient in meeting new demands.

The ANT certainly applies, on the basis of including non-human factors, in this case the excessive drug markets and the excessive HIV epidemic. As well, the hypotheses of Serduelt [36] are confirmed. On the other side, the ACF theory as applied by Kübler [39] allows to describe the competition between the 'innovators' and the opposition, and it also helps to understand the interaction of both these networks in shaping the innovations in order to have less unintended negative effects. Finally, the societal learning theory shows the need how to stabilise the process of change in new structural systems as a secondary process. 
Within this overall development, the preparation and implementation of heroin maintenance treatment can be understood as the result of specific actor networks and coalitions. A first proposal for introducing this approach was made 1988 in national parliament, but without success. André Seidenberg, a general practitioner in Zurich city, consulted by many drug users, took up the proposal and convinced the head of the social department in the city administration; he also implemented the first lowthreshold methadone maintenance clinic. The City Council took the proposal to the Federal Council. At the same time, the Cantonal Government mandated experts to visit and report on the British practice of heroin prescription in its traditional form and in an innovative approach prescribing smokable heroin. The Sub-commission on Drug Issues of the Federal Narcotic Commission mandated an expert to review all international experience with prescribing narcotics [41], and finally mandated another expert to design a scientific study [42]. The concept had to pass by the Narcotic Commission and the Federal Office of Public Health before being submitted to the Federal Council. This process included a range of interactions between medical and law experts, local and national politicians in order to get fine-tuning and growing acceptance of the project. It can best be understood as a prominent example of the ACF theory.

\section{Knowledge Brokering in the Consolidating Phase}

Even before the end of the PROVE study, in November 1994, the Federal Department of Home Affairs gave a Commission of experts [18] the mandate to present a report and recommendations for a revision of the Narcotic Law. The Commission held sessions to gather information on the state of specialised knowledge, and it organised hearings on the medical prescription of narcotics and on custodial care, which were attended by Swiss and foreign experts and other local stakeholders.

The Commission's report can be characterised as a major effort in knowledge brokering between experts and politicians. It pointed out that there were many more problems associated with the use of legal products with addictive properties (medication, tobacco and alcohol) than with the use of illegal drugs. According to the Commission, it was difficult to justify making a distinction between legal and illegal drugs, at least from the perspective of health policy. The recommendations reflected an effort to counteract the stigmatisation of the user and to give him access to the healthcare delivery system without prejudice.

Understanding Swiss Drug Policy Change
In detail, the following recommendations were proposed:

- The Confederation, cantons and communes should be required to implement preventive measures. The Confederation should also be given a policy coordination role with a view to standardise prevention strategies, and should adopt the necessary legal measures to ensure the funding of information and awareness campaigns.

- People with drug addiction should have access to institutions offering harm reduction and coping skill programs, so that they can improve their health and living conditions. Legal measures should be put in place so that the Confederation can require cantons and communes to set up such institutions, and coordination should be handled by the Confederation. Financial incentives should be offered to the cantons and communes.

- Treatment that meets the specific needs of people with drug addiction should be available at in- and out-patient centres. There should be better cooperation between the various treatment programs, and drug addiction programs should be better integrated into the overall health and social assistance network. The Confederation should obtain the powers it requires to coordinate treatment programs, make recommendations on minimum standards set as benchmarks.

- HAT trials having yielded positive results and furthering scientific confirmation of the research, this novel therapeutic approach (targeting a specific group of patients) should be included in the range of treatments offered for addiction disorders. In this event, the Narcotics Act should be amended by removing heroin from the list of non-prescribable substances. The Federal Council should also be given the authority to determine the general conditions applying to such prescriptions.

- Given the rapid developments and new problems that are occurring, the Confederation should strengthen its efforts to encourage research in the area of drugs. A clear legal framework should be established and, most importantly, sufficient funds must be made available. The Narcotic Law should include a provision that would exempt the Federal Council from complying with the legislation under specific general conditions in order to authorise trials.

Another expert committee, the Sub-Commission for Drug Issues of the Federal Narcotic Commission, reported that the harm reduction approach was the most suitably adapted model to the Swiss situation which, consid- 
ering the numerous social values and direct democracy, required a policy that could integrate different values and be sufficiently flexible to react rapidly and effectively to change [43].

The Federal Council adopted the proposed recommendations. To give it legal basis, the Federal Council proposed a referendum on the issue. National drug policy gatherings in 1991 and 1995 [10] provided an impetus to involve all the main political and professional actors in an intensive debate; the meeting reports opened the debate to the media and the general public, which led to a widespread acceptance of the pragmatic policy approach.

Three major political parties played an important role in the processes described here: Liberals (Freisinnig-demokratische Partei), Christian socialists (Christlich-soziale Partei) and Social democrats (Sozialdemokratische Partei) formed a joined drug policy platform at national level, to support the Federal drug policy issued in 1991. Opposition came mainly from the People's party (Volkspartei). The same constellation was seen during the referenda.

The coalitions supporting harm reduction measures were initially only partially the same as the coalitions supporting heroin maintenance treatment. They worked in parallel. Later on, they merged when a consolidation of the new drug policy was at stake.

As described under the 'Schild Commission', the stakeholders in favour of the new policy waited for the outcomes of the research project on heroin maintenance and planned to use the positive outcomes during the referenda.

The role of media for reporting on the process in all its phases and aspects should not be underestimated. Especially before the various national and local referenda on the continuation of heroin maintenance treatment, extensive reports on expert opinion, on research findings, on public controversies were published in national and local papers, and broadcast on radio and television.
In the Swiss political system with its frequent referenda, the knowledge brokering function of the media is indispensable.

\section{Conclusions}

Coalitions of change actors across stakeholder groups from many professions and politicians on various levels succeeded in formulating and starting initiatives for a new drug policy and its innovations. Clear shared objectives and a common feeling of urgency brought the coalitions together. For the preparation and implementation of heroin maintenance treatment, such coalitions and advocacy networks were indispensable. They will also be inevitable for the introduction of other innovations in the health field and related areas.

Brokering initiatives, characterised by a carefully designed process for bringing researchers and policymakers together and appropriate institutional embedding, have significant impacts on health policy $[24,25]$. In the case of Switzerland, the Confederation took a leading role by facilitating communication, encouraging scientific knowledge and bringing the various stakeholders on a platform to deliver a consensual political policymaking basis. This was facilitated by the Swiss direct democracy system, needing a high level of argumentation and a participatory approach to implement the new drug policy in a highly emotional context. Media had a critical role in fostering awareness and opinion shaping in the population at large. The result in this case was unequivocal: in November 2008, Swiss citizens voted on the 2 nd revision of the Narcotic Law, which included the heroin maintenance treatment. It was well accepted.

In absence of comparable policy analyses from other countries such as the Netherlands, Germany, Spain and the UK, the Swiss example presented here can only be used as an example and starting point for comparative research.
References

Eur Addict Res 2014;20:200-207 DOI: $10.1159 / 000357234$ tions of Narcotics for Heroin Addicts. Main Results of the Swiss National Cohort Study. Basel, Karger, 1999.

Dobler-Mikola A, Uchtenhagen A: Feasibility, safety, and efficacy of injectable heroin prescription for refractory opioid addicts: a follow-up study. Lancet 2001;358:1417-1423.

$\checkmark 2$ van den Brink W, Hendriks VM, Blanken P, Koeter MW, van Zwieten BJ, van Ree JM: Medical prescription of heroin to treatment resistant heroin addicts: two randomised controlled trials. BMJ 2003;327:310-312.

3 Uchtenhagen A, Dobler-Mikola A, Steffen T, Gutzwiller R, Blättler R, Pfeifer S: Prescrip-
-4 Uchtenhagen A, Gutzwiller F, Dobler-Mikola $A D$, Steffen T: Programme for a medical prescription of narcotics. A synthesis of results. Eur Addict Res 1997;3:160-163.

5 Oviedo-Joekes E, Brissette S, Marsh DC, Lauzon P, Guh D, Anis A, Schechter MT: Diacetylmorphine versus methadone for the treatment of opioid addiction. N Engl J Med 2009; 361:777-786. 
-6 Strang J, Metrebian N, Lintzeris N, Potts L, Carnwath T, Mayet S, Williams H, Zador D, Evers R, Groshkova T, et al: Supervised injectable heroin or injectable methadone versus optimised oral methadone as treatment for chronic heroin addicts in England after persistent failure in orthodox treatment (RIOTT): a randomised trial. Lancet 2010; 375:1885-1895.

7 Naber D, Haasen C: Das Bundesdeutsche Modellprojekt zur heroingestützten Behandlung Opiatabhängiger. Abschlussbericht zur klinischen Vergleichsstudie zur Heroin- und Methadonbehandlung. Hamburg, ZIS der Universität Hamburg, 2006.

8 Ferri M, Davoli M, Perucci CA: Heroin maintenance for chronic heroin-dependent individuals. Cochrane Database Syst Rev 2011;CD003410.

9 Strang J, Groshkova T, Metrebian N: New heroin assisted treatment. Recent evidence and current practices of supervised injected heroin treatment in Europe and beyond. Luxembourg, Publications Office of the European Union, 2012.

10 Uchtenhagen A: Heroin-assisted treatment in Switzerland: a case study in policy change. Addiction 2010;105:29-37.

-11 Perneger TV, Giner F, del Rio M, Mino A: Randomised trial of heroin maintenance programme for addicts who fail in conventional drug treatments. BMJ 1998;317:13-18.

-12 Bammer G, van den Brink W, Gschwend P, Hendriks V, Rehm J: What can the Swiss and Dutch trials tell us about the potential risks associated with heroin prescribing? Drug $\mathrm{Al}$ cohol Rev 2003;22:363-371.

13 Sprumont D: Ethical evaluation of heroinprescription research: an insider's view. Am J Bioeth 2002;2:63-64.

14 Ostini R, Bammer G, Dance PR, Goodin RE: The ethics of experimental heroin maintenance. J Med Ethics 1993;19:175-182.

15 Swiss Federal Council: Bundesratsbeschluss über Massnahmen des Bundes zur Verminderung der Drogenprobleme vom 20. Februar 1991. Bern, Bundeskanzlei, 1991.

16 Federal Office of Public Health: Massnahmen des Bundes zur Verminderung der Drogenprobleme: Ein Grundlagenpapier des Bundesamtes für Gesundheitswesen. Bern, Federal Office of Public Health, 1991.
17 Ali R, Auriacombe M, Casas M, Cottler L, Farrell M, Kleiber D, Kreuzer AR, Ogbome A, Rehm J, Ward P: Report of the External Panel on the Evaluation of the Swiss Scientific Studies of Medically Prescribed Narcotics to Drug Addicts. Geneva, Report to the World Health Organisation, 1998.

18 Rapport de la Commission d'experts pour la révision de la loi fédérale du 3 octobre 1951 sur les stupéfiants à l'attention de la cheffe du Département fédéral de l'intérieur. Berne, Office fédéral de la santé publique, 1996.

19 Canadian Health Services Research Foundation. The theory and practice of knowledge brokering in Canada's health system. 2003.

20 Jackson-Bowers E, Kalucy L, Mc Intyre E: Focus on... Focus on knowledge brokering. Adelaide, Primary Health Care Research and Information Service, 2006.

21 van Kammen J, de Savigny D, Sewankambo $\mathrm{N}$ : Using knowledge brokering to promote evidence-based policy-making: The need for support structures. Bull World Health Organ 2006;84:608-612.

22 Ritter A: How do drug policy makers access research evidence? Int J Drug Policy 2009;20: 70-75.

23 Anderson LM, Brownson RC, Fullilove MT, Teutsch SM, Novick LF, Fielding J, Land GH: Evidence-based public health policy and practice: promises and limits. Am J Prev Med 2005;28:226-230.

24 Hanney SR, Gonzalez-Block MA, Buxton MJ, Kogan M: The utilisation of health research in policy-making: concepts, examples and methods of assessment. Health Res Policy Syst 2003;1:2.

25 Gregrich RJ: A note to researchers: communicating science to policy makers and practitioners. J Subst Abuse Treat 2003;25:233-237.

26 Uchtenhagen A: The role of coalitions in drug policy. Some theoretical and observational considerations. Adicciones 2011;23:183-187.

27 Sabatier P: The advocacy coalition framework: revisions and relevance for Europe. J Eur Public Policy 1998;5:98-130.

28 Freeman L: The Development of Social Network Analysis. Vancouver, Empirical Press, 2006.
29 May CR, Mair F, Finch T, MacFarlane A, Dowrick C, Treweek S, Rapley T, Ballini L, Ong BN, Rogers A, et al: Development of a theory of implementation and integration: Normalization Process Theory. Implement Sci 2009;4:29.

30 Wejnert B: Integrating models of diffusion of innovations: a conceptual framework. Annu Rev Sociol 2002;28:297-306.

31 Rogers EM: Diffusion of Innovations, ed 5. New York, Free Press, 2003.

32 Waddell S: Societal Learning and Change. Sheffield, Greenleaf Publishing, 2005.

33 Law J, Hassard J: Actor Network Theory and After. Oxford, Blackwell, 1999.

34 latour B: Reassembling the Social: An Introduction to Actor-Network-Theory. Oxford, Oxford University Press, 2005.

35 Callon M, Lascoumes P, Barthe Y: Acting in an Uncertain World. An Essay on Technical Democracy. Cambridge, MIT Press, 2009.

36 Serduelt U: Politiknetzwerke in der städtischen Drogenpolitik von Bern, Chur, St. Gallen und Zürich. Zurich, University of Zurich, 2000

37 Kübler D: Beyond nimbyism. Urban conflict resolution in Swiss drug policies; in Khan U: Participation beyond the Ballot Box European Case Studies in State-Citizen Dialogue. London, UCL Press, 1999, pp 43-64.

38 Kübler D: Politique de la drogue dans les villes suisses entre ordre et santé. Analyse des conflits de mise en oeuvre. Paris, L'Harmattan, 2000.

39 Kübler D: Understanding policy change with the advocacy coalition framework: an application to Swiss Drug Policy. J Eur Public Policy 2001;8.

40 Grob P: Zürcher 'Needle Park'. Ein Stück Drogengeschichte und -politik 1968-2008. Zurich, Chronos, 2012.

41 Mino A: Scientific Analysis of the Studies on Heroin or Morphine Controlled Delivery. Bern, 1990.

42 Uchtenhagen A, Gutzwiller F, Dobler-Mikola A: General study design and implementation rules. Foundation for social therapy, the connection between research and practice in drug therapy. Drogalkohol 1994;187-198.

43 Subcomission for Drug Issues: Drug Policy Scenarios. Bern, 1996 